\title{
Políticas públicas e a construção do comum: interrogando práticas PSI
}

Public policies and the construction of common: interviewing practices PSI

Las políticas públicas y la construcción de comunes: cuestionando las prácticas PSI

\section{Maria Elizabeth Barros de Barros}

Universidade Federal do Espirito Santo, Vitória, ES, Brasil.

\section{Ellen Horato do Carmo Pimentel}

Universidade Federal do Espírito Santo, Vitória, ES, Brasil.

\section{Resumo}

Os psicólogos têm desenvolvido muitos trabalhos em Secretarias de Saúde, de Assistência Social, de Educação Municipal e Estadual, dentre outras. Este artigo se tece em meio a essa inserção, buscando colocar em discussão as práticas psi e a constituição de políticas públicas. Inicia com uma discussão sobre o conceito de política, trazendo contribuições de alguns pensadores, de forma a indicar uma diretriz para pensar as práticas em políticas públicas. Apresenta alguns elementos para reflexão sobre uma concepção de comum que não se dissocia de um modo de fazer política pública. Conclui com uma experiência realizada por psicólogos no Espírito Santo, no âmbito das políticas públicas de saúde. Efetua uma aposta na produção do comum nas práticas em Psicologia constituindo-se como multiplicidade composta por diferenças singulares em um novo modo de governo.

Palavras chave: Políticas Públicas, Práticas Psicológicas, Saúde Pública.

\begin{abstract}
Psychologists have developed many works in health departments, of social welfare, education in city and state, among others. This article happens in this insertion, trying to bring psi practice discussion and formation of public policy. It begins a discussing the concept of politics bringing contributions of some thinkers, to indicate a guideline for thinking practices in public politics. Below are some elements to think about a common conception that does not dissociate in a manner of making public politic. Conclude with an experiment conducted by
\end{abstract}


psychologists in the Espirito Santo within the public health politics. When they look into the workings of the constitution of the public dimension, it also making a bet on the production of the common practices in psychology. This common that it builts in a public politic is constituted of multiple composed by unique differences that find in theare common in the management of a new mode of government.

Keywords: Public Policy, Psychological Practices, Public Health.

\section{Resumen}

Los psicólogos han desarrollado muchos trabajos en los departamentos de salud, de bienestar social, de educación en la ciudad y el estado, entre otros. En este artículo se teje en medio de esta inserción, tratando de poner en discusión prácticas psi y la formación de las políticas públicas. Comienza con una discusión del concepto de la política, por lo que las contribuciones de algunos pensadores, para indicar una guía para las prácticas pensando en las políticas públicas. A continuación se presentan algunos elementos para pensar en una concepción de común que no se disocia de manera de hacer política pública. Concluí con un experimento realizado por los psicólogos en el Espíritu Santo dentro de las políticas de salud pública. Cuando se fija en el funcionamiento de la constitución de la dimensión pública, también está haciendo una apuesta en la producción de las prácticas comunes en la psicología. Esto se basa en una política pública común, ya que está compuesto por múltiples diferencias únicas que son comunes en la gestión de un nuevo modo de gobierno.

Palabras clave: Política Pública, Prácticas Psicológicas, Salud Pública.

Somos cinco amigos. Certa vez saímos um
atrás do outro de uma casa. Logo de início
saiu o primeiro e se pôs ao lado do portão
da rua, depois saiu o segundo, ou melhor:
deslizou leve como uma bolinha de
mercúrio, pela porta, e se colocou não
muito distante do primeiro, depois o
terceiro, em seguida o quarto, depois o
quinto. No fim, estávamos todos formando
uma fila, em pé. As pessoas voltaram a
atenção para nós, apontaram-nos e
disseram: 'Os cinco acabam de sair
daquela casa'. Desde então vivemos juntos; seria uma vida pacífica se um sexto não se imiscuísse sempre. Ele não nos faz nada, mas nos aborrece, e isso basta: por que é que ele se intromete à força onde não querem saber dele? Não o conhecemos e não queremos acolhê-lo. Nós cinco também não nos conhecíamos antes e, se quiserem, ainda agora não nos conhecemos um ao outro; mas o que entre nós cinco é possível e tolerado não o é com o sexto. Além do mais somos cinco e não queremos ser seis. E se é que esse estar junto constante tem algum sentido, para nós 
cinco não tem, mas agora já estamos reunidos e vamos ficar assim; não queremos, porém, uma nova união justamente com base nas nossas experiências. Mas como é possível tornar tudo isso claro ao sexto? Longas explicações significariam, em nosso círculo, quase uma acolhida, por isso preferimos não explicar nada e não o acolhemos. Por mais que ele torça os lábios, nós o repelimos com o cotovelo; no entanto, por mais que o afastemos, ele volta sempre (Kafka, 2002, p. 112-113).

Não por acaso, escolhemos esse trecho da obra de Kafka para abrir este artigo. Ele nos lança no desafio que aqui intentamos perseguir: o da constituição do coletivo em meio às malhas das forças privatizantes. Indicamos, logo de partida, a posição assumida no texto: uma aposta na produção do comum nas práticas em Psicologia e, em especial, quando atuamos com políticas públicas. Aliançamo-nos a esse movimento de uma boa teimosia do sexto, que aponta para a impermanência dos arranjos e para a sempre necessária abertura ao Fora, às forças do coletivo condição de possibilidade na constituição de políticas públicas.

Os psicólogos têm desenvolvido muitos trabalhos em Secretarias de Saúde, em Secretarias de Assistência Social, em Secretarias de Educação Municipal e Estadual, dentre outras. A tendência de muitas práticas em Psicologia tem sido tomar como foco o sujeito a-histórico, uma consequente naturalização dos aspectos psicológicos e a sociedade, entendida como desenho previamente constituído, de forma dicotômica. Os chamados "aspectos subjetivos" são considerados a partir de uma linhagem teórico-metodológica que afirma uma ontologia pautada em substancialismos que considera o ser uma unidade fundada sobre si mesma. Partem de um indivíduo já constituído, sem capacidade de se "defasar" em relação a si próprio. Tais práticas operam privilegiando o sujeito, sua "personalidade", por meio de estratégias privatizantes e pautadas em modelos teóricos descolados da concretude das situações onde se intervêm. A sociedade, por sua vez, refere-se a uma unidade pronta, conjunto de pessoas com desenho previamente construído e dado de uma vez por todas.

Como trabalhar sem operar a tradicional dicotomia indivíduo-sociedade? Como desdobrá-la em paradoxo? O desafio é construir estratégias de trabalho que não se aliem a propostas que partem de separações entre individual e social, coletivo e singularidade, tão caras a certa tradição nesse campo. O texto visa a indicar algumas pistas para o trabalho do psicólogo no âmbito das políticas públicas, 
recusando as grandes divisões de perspectivas naturalizadas.

Entendemos que os processos de subjetivação são múltiplos, heterogenéticos e podem resistir às diferentes tentativas de modulações que caminham rumo à homogeneização das formas de existência. Os sujeitos inventam outros modos de existir, colocam em rede sua sinergia e ativam uma potência de singularização. Trata-se, aí, do movimento de "outrarmonos" que advém da possibilidade de acessar esse plano de constituição, essa multiplicidade que é nossa matéria, que é a pedra de toque para pensarmos o coletivo.

Ao invés de sociedade, pensar coletivos como um plano de forças que não se confunde com a noção de social ou de sociedade - estas comprometidas com categorias identitárias. O termo coletivo não diz de uma quantidade de pessoas, e sim de uma impessoalidade capaz de afirmar o "para todos e qualquer um" concernente à dimensão pública das práticas nos mais diversos serviços. De acordo com Escóssia e Tedesco (2009), a formulação do conceito de coletivo - tal como o efetuam Foucault, Simondon, Deleuze, Guattari e Lourau - se faz fora da malha que dicotomiza indivíduo e coletivo. Coletivo não se refere, portanto, a uma unidade pronta; ao contrário, diz de um exercício de composição, um trabalho de construção de constituição de um mundo comum que não está dado de uma vez por todas.

Este artigo se tece em meio a essas questões. Com esse objetivo, traça um caminho. Iniciamos com uma discussão sobre o conceito de política, trazendo contribuições de alguns pensadores, de forma a indicar uma diretriz para pensar as práticas em políticas públicas. Em seguida, apresentamos alguns elementos para pensar uma concepção de comum que não se dissocia de um modo de fazer política pública. Concluímos com uma experiência realizada por psicólogos no Espírito Santo, no âmbito das políticas públicas de saúde. Política, aqui, entendida como discussão do mundo no qual desejamos viver. Afinal, é o modo como concebemos e perseguimos esse mundo que define o tipo de política que praticamos.

Nossa tese é a de que as políticas de governo e os estabelecimentos onde atuamos, com seus contornos definidos, são efeitos-resultados de uma composição do plano das formas com o plano movente das forças, que é a dimensão instituinte. As formas passam a ser tomadas como resultado desse jogo de forças e correspondem a coagulações, a conglomerados de vetores. Então, a direção passa a ser a de interferir nos processos que constituem as realidades e não partir 
das realidades como aspectos sempre já dados.

\section{Políticas estatais e políticas públicas: no rastro dos interstícios}

Conforme Bobbio (2007), a palavra política é derivada de polis (politikós) e se reporta a tudo o que se refere à cidade. Em Aristóteles, encontramos, em sua obra "Política", uma concepção segundo a qual política diz respeito à natureza, funções e divisão do Estado, assim como às várias formas de governo. É arte ou ciência de governar e de reflexão sobre as coisas da cidade.

Ainda segundo Bobbio (2007), na modernidade, o termo política perde esse sentido e é substituído por expressões como ciência do Estado, ciência política, designando atividade ou conjunto de atividades que têm como referência a polis, que passa a ser entendida como o Estado, os próprios sujeitos ou, ainda, as ações, como conquistas, manutenção, defesa, derrubada ou destruição do poder estatal. Portanto, em todas as suas modulações, o que se mantém é a ideia de que política é uma atividade ou práxis humana e o poder político é o exercício de poder, e essa relação, continua Bobbio (2007), se expressaria de inúmeras maneiras: relação entre governantes e governados, soberano- súditos, Estado e cidadãos, autoridadeobediência. É exercido pelo interesse de quem governa e de quem é governado, e é diferente do poder despótico, que se exerce apenas pelo interesse do senhor.

Benevides e Passos (2009) indicam que, no entendimento da palavra política como polis, arte e ciência de governar, o Estado comparece como um de seus aspectos. E mais, no contemporâneo, é justamente esta correlação entre prática política, atividades do Estado e de governo que tem sido privilegiada. A atividade política, entendida dessa forma, ajuda-nos a compreender as diferenças entre "política de Estado" e "política de governo". Uma política de Estado se constituiria por meio de ações de cunho estruturante nas quais os governantes que se alternam no poder devem garantir que tal política seja efetivada, devendo seguir e cumprir determinadas linhas, programas e projetos. Ultrapassa a política de governo e é institucionalizada, pois, ainda que se troque de governo, ela permanece. O SUS, por exemplpo, é uma política de Estado instituído pela Carta Magna de 1988.

Por outro lado, as políticas de governo podem sofrer quebra de continuidade e estão articuladas em função de conjunturas. Têm institucionalização mais fraca e menor durabilidade. São pensadas a partir de um projeto específico 
de forças políticas que assumem o aparelho de Estado, dependem do arranjo de forças e das escolhas políticas, que determinam algumas ações e não possuem garantia legal de continuidade. Sua continuidade depende de sua força nas diferentes esferas sociais, pois, para que uma política de governo possa ir além do período de gestão de um governo, é necessária uma efetiva participação social.

$\mathrm{Na}$ contramão desses movimentos que equacionam em igualdade atividade política e atividades de Estado e governo, vemos, no texto "Por uma política de narratividade" (2009), Eduardo Passos e Regina Benevides apontarem a necessidade de ampliarmos o sentido do termo política para além do domínio das práticas relativas ao Estado. Caberia, então, chamarmos política a atividade humana que, ligada ao poder, coloca em relação sujeitos, articulando-os segundo regras ou normas não necessariamente jurídicas ou legais. Desloca-se, assim, a política de um centro de poder (o Estado, uma classe), considerando também seu exercício em arranjos locais, por microrrelações, indicando a direção micropolítica das relações de poder (Foucault, 1977).

E a ideia de público? A que tem se vinculado? Como discutir a concepção de público de maneira a não restringi-la às políticas de Estado e de governo?

Segundo Romano (2005), a ideia de público emerge no século XVIII, após a Revolução Americana e Francesa, quando foi concedida ao poder de Estado a base que lhe permite impor as políticas a serem praticadas e assumidas pela sociedade civil. Caberia ao Estado, portanto, a universalização do público.

No que diz respeito ao caso brasileiro, o autor afirma que não temos um Estado federativo nem democrático e as políticas que determina não passam pelas três esferas - Legislativo, Executivo e Judiciário -, e menos ainda pela sociedade civil. O Estado brasileiro, surgido contra a Revolução Francesa, seria uma tentativa de prevenir supostos "desmandos democráticos" advindos das Revoluções Francesa e Americana. A ideia mestra desta instauração antidemocrática seria a tese segundo a qual um poder moderador e neutro seria necessário para ajudar a amortecer choques entre os três poderes no Brasil. Romano (2005) avalia, entretanto, que esse poder não é neutro e se tornou prerrogativa do chefe de Estado que, pelo Executivo, controla o Parlamento e o Judiciário. O poder moderador seria o do presidente da República, o que confere até hoje aos chefes de Estado poderes ditatoriais, ou seja, concentração das 
decisões no poder central e maior concentração dos poderes no Executivo. Temos, assim, um federalismo estranho, que não permite diversidade nos ordenamentos legais e nas políticas públicas de Estados e Municípios.

Romano (2005) atenta para a uniformidade normativa que abstratamente reúne povos, culturas, situações diversas de modo igual, por meio de portarias de saúde e educação, por exemplo, que regem todo o País de norte a sul, indiscriminadamente. Tal status quo vai à contramão de práticas sociais e políticas transparentes e democráticas.

Até aqui a noção de público está confundida com a ideia de estatal. A questão talvez fosse: qual o caráter público das ações estatais? Ora, sabemos que o fato de ser estatal não garante o caráter público das práticas. $\mathrm{O}$ caráter público dos projetos e programas se faz quando expressam interesses coletivos, que se opõem ao funcionamento particularizante com seus totalitarismos e individualizações.

Para Sader (2005, p. 46), o público assumiu formas confundidas com estatal em função de uma ambiguidade da crítica a uma concepção liberal de Estado. "Nação, classe, comunidade foram invocadas para promover renúncias ao plano individual muitas vezes em nome do público, mas na realidade falando em nome do estatal".
Historicamente, diz ele, o primado do público representou a expansão dos poderes de intervenção do Estado, na sua capacidade de regular o mercado.

Ainda com referência a esta questão da dimensão pública das políticas no Brasil, Sader (2005) afirma que a ideia de público aparece pela primeira vez em 1930, inscrita no Estado, que antes se assemelhava a uma "coalizão de elites no poder". A Revolução de 30 vinha romper com a hegemonia das oligarquias regionais que já davam sinal de sua incapacidade de produzir um modelo hegemônico para o País, não conseguindo, inclusive, se reproduzirem como "classes primárioexportadoras". Daí a construção de um Estado com uma política de industrialização e a construção de um bloco social de apoio popular ao governo que se efetivou pela primeira vez na história do Brasil. Tal apoio, é importante que se diga, era de caráter passivo e atrelava o movimento sindical legal ao Estado. Para Sader (2005), a ausência de organização autônoma da classe trabalhadora, assim como as formas de participação político-democráticas, segundo suas análises, não autorizariam dizer que tal modelo integrasse uma dimensão pública como aspecto central desse modelo, que tinha uma marca estatista-nacional. Em 1964, esse nacional- 
estatismo dá lugar ao estatismo-militar, enfraquecendo o público e privilegiando o mercantil, afirma o autor.

As análises de Sader (2005) nos indicam, assim, que, por definição, o Estado não é público nem privado, mas campo de disputa entre essas duas esferas, não podendo, sobretudo, reduzir o público ao estatal.

Nessa linha de análise, o autor nos mostra que, com a hegemonia neoliberal, a partir da década de 80, houve uma transformação importante nesse debate estatal-privado que deslocou um elemento que antes fazia parte dessa polarização, que é o público. Segundo Sader (2005, p. 43):

A crítica ao 'estatismo', paralelamente à apologia do mercado, dos espaços privados, da 'sociedade civil', tiveram como principal efeito - além da desvalorização do primeiro (pólo-estatal) em favor do segundo (pólo - privado), - o deslocamento do outro elemento que antes fazia parte integrante da polarização - o público.

Tal deslocamento acabou favorecendo a exaltação do polo privado, desqualificando o Estado e fazendo desaparecer o público. Assim, os dois termos da dicotomia podem ser definidos independentemente um do outro ou ter sua definição centrada num deles, sendo o outro definido por exclusão. $O$ privado passa a ser o não público, e os dois termos são definidos de forma antagônica e mutuamente dependentes. A definição de um termo está vinculada ao outro e ganha sentido por contraposição. "O interesse público é determinado imediatamente em relação e em contraste com o interesse privado e vice-versa" (Sader, 2005, p. 44). Há aqui uma diferença essencial na natureza entre público e privado, que seriam elementos contraditórios entre si. $\mathrm{O}$ público pertenceria ao grupo, à coletividade, à sociedade global; e o privado, ao que pertence a seus membros individuais, eventuais grupos minoritários, como a família, por exemplo.

Em nosso entendimento, o público se expressa pelas forças coletivas, logo essa esfera está potencialmente presente em qualquer governo, inclusive nos ditatoriais, ainda que não seja sua bandeira. Tal diferenciação pauta-se na dicotomia indivíduo-sociedade, da qual discordamos. Cabe destacar, ainda, que o Estado e os governantes não podem ser a única expressão do coletivo, o que seria privatização das políticas. Mesmo porque, como já apontado, ao apresentarmos o coletivo como uma pista para a constituição de políticas públicas, falamos de uma impessoalidade que se faz fora da malha que dicotomiza indivíduo e coletivo. 
É importante destacar o modo como uma política se constitui como pública, pois, uma vez que se ela se integra à máquina estatal, há o risco de uma captura política que pode se desdobrar num aspecto rígido, inflexível.

\section{Produzindo comum, produzindo política pública}

Uma política pública deve garantir a participação social em sua elaboração, planejamento, execução, monitoramento e ser estruturada e balizada por meio de lutas coletivas e interesses das diferentes dimensões do socius. Essa dimensão pública de uma política se atualiza como rede de relações multivetorializadas, exige interferências, transversalidade, cogestão e inclui sujeitos com necessidades, demandas.

As políticas públicas são orientadas por um modo de funcionamento capaz de indicar as singularidades para fora da ordem de serialidade e do unidimensionamento, e está além do Estado. Esse comum, que se constrói numa política pública, constitui-se como multiplicidade composta por diferenças singulares que encontram na gestão do comum um novo modo de governo.

Comum não é uma identidade, não se confunde com povo, nem é uniformidade como as massas; são as diferenças internas que devem fazer comunicar as diferenças e agir em conjunto. Aqui um paradoxo: uma multiplicidade social se comunica e age em comum ao mesmo tempo em que reverbera diferenças. Esse comum se faz como rede heterogênea, dispersa, complexa e multidirecional. Coletivo e singularidade não se excluem. Singularidade não é sinônimo de individualidade, pois esta última é relação do eu com uma realidade, transcende. Então, esse comum se faz não como materialização de forças hegemônicas que tendem a segmentar, individualizar, definir, demarcar, localizar, cerceando conexões de forças minoritárias que tendem a se exercer em outro sentido: faz-se por diferenciação e heterogênese, ou seja, gerando diferença e não homogeneidade e semelhaça.

Portanto, acessar esse plano comum não é apelar para elementos que conferem uma identidade ou unidade nem reforçar semelhanças de igualdade e permanência de pessoas consideradas como tendo uma mesma cultura, mesma história, comunhão de uma mesma crença abordada como um todo. Essa abordagem, que permeia políticas de Estado e de governo, lida com comunidade-indivíduo. Ao contrário, um fazer que se faz público produz um coletivo que trabalha para além de si e de suas 
fronteiras, acolhe e cuida da vida-outra (Gotardo, 2011).

$$
\text { O comum é, assim, abertura ao }
$$
Outro, composição de singularidades, acolhimento à multiplicidade, capacidade de diferir. É alargamento da capacidade de comunicar, de associar, compartilhar, forjar novas conexões e proliferar redes e tem, como condição, a abertura a uma multiplicidade de encontros que não se fecha a um conjunto de pessoas. Produz funcionamento difícil de capturar, pois se define pela não captura a formas preestabelecidas. Não é o que junta, mas se refere a um certo modo de viver junto, na diferença, não por sínteses inclusivas, mas disjuntivas, definindo-se pelo interstício (Gotardo, 2011).

Trabalhar com políticas públicas na esteira do que estamos afirmando é construir coletivamente estratégias de transformar para conhecer uma dada realidade que se constitui a partir de semióticas singulares, é incluir diferentes protagonismos. O psicólogo se encontraria em meio a um território que não conhece e não domina a semiótica. Com esse objetivo, trabalha com um método que se faz participativo, na medida em que coloca lado a lado todos os envolvidos no processo, fazendo aparecer as tensões e controvérsias, de modo a não neutralizar a recalcitrância daqueles com os quais trabalha. Coloca em análise a dinâmica institucional, indaga pressupostos e crenças, constitui rede, altera o padrão comunicacional.

A contração do coletivo, a constituição de grupalidade, é feita para além das dicotomias e das formas hegemônicas de organização da comunicação nas instituições. Desestabilizam-se os modos verticais e horizontais de funcionamento institucional, incluindo-se um terceiro eixo. Não mais fronteiras entre saberes e atores, mas atravessamento de diferentes semióticas, experiência da dimensão do coletivo. Esse modo de intervenção institucional constrói e faz aparecer o coletivo como experiência do comum, potencializando saberes até então excluídos. Tal caráter participativo e inclusivo se faz a partir da abertura experimentada pela rede ou pelo coletivo, alterando-se o padrão comunicacional entre os grupos de interesse envolvidos. A dimensão do coletivo extrapola qualquer fronteira preestabelecida, é zona de indiscernibilidade, não pertence exclusivamente a nenhum.

Comum, entendido como político, não é dado a priori, advém da experiência. Aqui outro paradoxo: o comum é heterogêneo. O comum é a jusante da experiência, acompanha práticas concretas, cria efeito de pertencimento, conjura o 
perigo de captura e sua construção se faz por transversalização - entendida aqui como plano que não se define nos limites estritos de uma identidade, de uma individualidade, de uma forma (esse saber, o meu saber, o saber que o outro tem e pode me transmitir), mas “[...] experimenta o cruzamento de várias forças que vão se produzindo a partir dos encontros entre os diferentes nós de uma rede de enunciação da qual emerge, como seu efeito, um mundo que pode ser compartilhado pelos sujeitos" (Passos \& Eirado, 2009, p. 115).

Latour (2007) propõe que utilizemos do conceito de articulação para pensar a constituição do comum. Articulação implica compor com elementos os mais diversos (livros, aparatos científicos, outras pessoas, músicas, enfim...) de forma a nos tornarmos mais interessantes, aprendendo a ser afetados pelos outros, e não apenas por nós próprios. E acrescenta Latour (2007, p. 43) que um sujeito se torna interessante à medida que ressoa com outros, quando é efetuado, “[...] posto em movimento por novas entidades cujas diferenças são registradas de formas novas e inesperadas". Nesse sentido, as articulações proliferam-se sem deixar de registrar diferenças e sem deixar de acolher e efetuar controvérsias.
Esse modo de pensar o trabalho em políticas públicas não se efetiva sem que se acesse o plano comum. Tal acesso implica a consideração da dimensão processual dos fenômenos e a construção de um mundo comum entre o psicólogo e os demais participantes do processo, ou seja, não produzindo distanciamento entre os envolvidos e interessados. O psicólogo sai da posição de quem julga a realidade, emite verdades sobre ela e passa a uma atitude de quem se interessa e cuida.

\section{Desafios na construção de uma política pública em saúde}

Em experiência no município de Cariacica/ES, um grupo de psicólogos tem realizado um trabalho de apoio à regionalização da saúde, seguindo uma das diretrizes organizacionais do Sistema Único de Saúde (SUS), que é uma política de Estado. Surge com o objetivo de superar as dificuldades enfrentadas no processo de institucionalização do SUS. O processo de regionalização prevê a territorialização dos serviços e objetiva o fortalecimento da Atenção Básica. Esse âmbito de atenção à saúde está direcionado ao desenvolvimento de práticas gerenciais e sanitárias democráticas dirigidas a populações de territórios bem delimitados, pelas quais se assume a responsabilidade sanitária, 
considerando a dinamicidade existente no território em que vivem essas populações (Brasil, 2006). Nesse sentido, a territorialização permite o conhecimento das áreas de abrangência das Unidades Básicas de Saúde (UBSs), possibilita a identificação da população adscrita em cada território e o planejamento local de ações em saúde, o que significa privilegiar a qualidade dos cuidados em saúde nos territórios em suas singularidades: mulheres, jovens, crianças etc.

Com esse objetivo, alguns movimentos desse projeto têm se efetivado no caminho de construção de estratégias que incluam usuários e trabalhadores da rede de saúde de Cariacica na discussão sobre o processo de territorialização em saúde, no âmbito da Atenção Básica desse município. Ao pontuarmos que nos debruçamos sobre uma metodologia pautada na inclusão e lateralização, indicamos que, ainda que a regionalização seja uma direção do trabalho, o que se mostra precioso é o modo como nos dispomos ao trabalho em curso.

Ao falarmos de um processo de regionalização construído por meio da discussão com os diferentes atores, faz-se necessário colocar em questão a própria conceitualização de território. Entendido como uma categoria de análise social, o território deve ser pensado a partir de seus usos, de suas dinâmicas de apropriação social. Como aponta Santos (2000, p. 22), o território torna-se uma ferramenta de trabalho da analítica social "[...] quando o consideramos a partir do seu uso, a partir do momento em que o pensamos juntamente com aqueles que dele se utilizam". A pertinência da utilização do conceito de território na análise das dinâmicas sociais vincula-se exatamente quando esse conceito é utilizado para ressaltar seu uso coletivo. Então, se entendemos o território como vivido e vivo como agente que transforma e é transformado no concreto das ações, passamos a considerá-lo fundamental ao pensarmos as políticas públicas de saúde.

Entender território como espaço relacional significa compreender que o espaço

\footnotetext{
[...] não é nem uma coisa em si, nem um sistema de coisas, mas uma realidade relacional: coisas e relações juntas. O espaço deve ser considerado um conjunto indissociável, de que participam de um lado, certo arranjo de objetos geográficos, objetos naturais e objetos sociais, e, de outro, a vida que os preenche e os anima, ou seja, a sociedade em movimento (Santos, 2008, p. 27-28).
}

Entendemos, assim, que o processo de territorialização implica não apenas a 
proposição de área de abrangência pelas UBSs do município de Cariacica, mas também mudanças na organização da rede de saúde, nas formas de trabalhar, de acessar os serviços, de habitar no espaço e de gerir os processos em curso.

O cenário político-econômico do município, particularmente no campo da saúde, pode ser expresso pelo alijamento de parte de seus moradores do acesso a bens e serviços nessa área. A descontinuidade e fragmentação das ações, bem como a forma de ocupação do território geográfico desse município operam marcas de fragilidade na formulação e implementação de Políticas Públicas no campo da saúde. Alguns fatores contribuem para isso. Destacamos, para os objetivos deste artigo, a fragilidade dos processos de inclusão dos usuários na discussão sobre a saúde no município. Tendo por desafio a constituição de coletivos engajados na construção do mapa de territorialização em saúde no âmbito da Atenção Básica desse município, efetivouse uma pactuação de parceria entre a Secretaria de Saúde do Município de Cariacica (Semus), Ministério da Saúde e Departamento de Psicologia da Universidade Federal do Espírito Santo (Ufes). O trabalho se efetiva por meio de apoio institucional no processo de territorialização, compondo equipes de referência junto com o Grupo de Trabalho de Humanização da Secretaria de Saúde, propondo discussões nas UBSs que incluam todos aqueles envolvidos no campo da saúde no município. A proposta é criar e implementar espaços coletivos de debates sobre a territorialização da saúde em Cariacica, o que entendemos como práticas de política pública.

Os psicólogos têm trabalhado a partir dos princípios e diretrizes da Política Nacional de Humanização da Atenção e da Gestão do SUS (PNH), vinculada ao Ministério da Saúde, que tem como proposta efetivar-se como uma política que atravessa as diferentes ações e instâncias gestoras do SUS. Aposta na indissociabilidade entre os modos de produzir saúde e os modos de gerir os processos de trabalho, entre produção de saúde e produção de subjetividade, entre clínica e política (Brasil, 2009). A PNH configura-se, portanto, como uma estratégia de interferência nos processos de produção de saúde e de sujeitos. Para tanto opera com os princípios de transversalidade, indissociabilidade entre atenção e gestão e também se vale de diretrizes, tais como: cogestão, clínica ampliada, acolhimento, saúde do trabalhador, direitos dos usuários, ativação das redes sociais. Nessa perspectiva, trabalha na perspectiva da inclusão dos 
diferentes sujeitos nas práticas em saúde (gestores, trabalhadores e usuários) no sentido da produção de autonomia e democratização nas relações e corresponsabilidade, assim como na inclusão de movimentos sociais e de analisadores sociais no processo de produção de saúde - o que se caracteriza, portanto, como um método de tríplice inclusão (Brasil, 2009).

Os encaminhamentos se fazem na efetivação da humanização como ethos posicionamento ético-político - na condução do processo de territorialização. Passos e Benevides (2005b, p. 393) convidam-nos a pensar a humanização como um "conceito-experiência" que se fortalece no fazer, que "[...] descreve, intervém e produz a realidade nos convocando para mantermos vivo o movimento a partir do qual o SUS se consolida como política pública, política de todos, política para qualquer um, política comum". Um dos desafios que se coloca, portanto, é a necessidade de afirmarmos a humanização como política pública, uma vez que

[...] da política de governo à política pública não há uma passagem fácil e garantida. Construir políticas públicas na máquina do Estado exige todo um trabalho de conexão com as forças do coletivo, com os movimentos sociais, com as práticas concretas no cotidiano dos serviços de saúde (Benevides \& Passos, 2005a, p. 391).

Se intentamos efetivar a PNH como política pública, é preciso nos comprometermos com a coletivização da gestão (Barros, 2007). A cogestão - aposta ético-política da PNH - é um modo de administrar que inclui o pensar e o fazer coletivo e, por isso, exige que se alterem os processos de definição das tarefas, responsabilidades e encargos assumidos pelos trabalhadores (Brasil, 2010). Para tanto, é preciso afirmar a gestão como inerente à atividade, às práticas cotidianas no trabalho. Ao afirmamos a gestão como algo indissociado das práticas de trabalhadores, usuários e "gestores", pretendemos nos distanciar da ideia de gestão como função centralizada na figura do gestor e nos departamentos administrativos. Assim, rompendo com a lógica dominante do mercado, a cogestão desponta no cenário das políticas públicas de saúde com vistas a "[...] reinventar e ampliar as possibilidades históricas de mudança" (Campos, 2000, p. 17).

Entendendo a necessidade de fortalecimento de coletivos que possibilitem a operacionalização da cogestão, o trabalho oferece Apoio Institucional à Gerência de Atenção Básica 
de Cariacica no processo de territorialização em saúde nesse município. A função de apoio institucional é exercida como método/dispositivo de intervenção em práticas de saúde pública (Barros, Guedes \& Roza, 2009), tendo por horizonte o fomento de "[...] espaços protegidos de fala e escuta para as equipes que experimentam processos de mudança em suas formas de gestão" (Brasil, 2010, p. 23).

A atuação dos apoiadores incide no engajamento no trabalho de forma a ampliar a capacidade de análise e intervenção dos coletivos e sujeitos forjados no processo. Trata-se, portanto, de uma tecnologia relacional que requer que o apoiador se coloque ao lado dos sujeitos na análise de seus processos de trabalho de modo a fomentar instrumentos que provoquem desvios, acolhendo e fortalecendo o que no grupo se desloca desses modelos. Do ponto de vista metodológico, o desafio é "[...] propor alteração dos modos de fazer, de trabalhar, de produzir no campo da saúde, entendendo ser esta uma tarefa para todos os que estão implicados na construção de políticas públicas de saúde" (Escossia, 2009, p. 692).

A estratégia do apoio institucional tomada como método de intervenção se expressa por uma função de apoio que dá passagem, persegue a criação de grupalidade, de forma a fortalecer e montar redes de coletivos. Lugar-função que instiga, lugar de passagem que viabiliza processos de desestabilização do que está instituído, fazendo emergir outros planos de afetos, de encontros, de constituição de redes de conversa, redes afetivas (Barros, Guedes \& Rosa, 2009).

\section{Fiando um comum: pistas interventivas}

A constituição de grupos heterogêneos, nesse debate construído no referido município, faz emergir interesses, saberes, experiências e modos de inserção diversos no processo de trabalho, convergindo em torno de objetivos e desafios comuns: como construir políticas públicas em saúde, comprometidas com a coletivização da gestão, com a publicização das relações entre trabalho (saberes), sujeitos (necessidades, desejos e interesses) e poderes (modos de relacionar saberes e sujeitos)? Como operar com os limites de infraestrutura apresentados nos serviços de saúde de Cariacica de modo a transpô-los, ao invés de tomá-los como impedimento à realização do trabalho de organização da rede, sem, contudo, apaziguar as indignações que deles decorrem? 
Construir práticas de saúde para as populações e, acima de tudo, com elas, exige mudanças no processo de constituição dos sujeitos nessas práticas. Somente com trabalhadores e usuários corresponsáveis é possível efetivar a aposta que o SUS faz na universalidade do acesso, na integralidade do cuidado e na equidade das ofertas em saúde, enfim, na constituição de políticas públicas de saúde. Discutir junto com os trabalhadores da rede de saúde do município de Cariacica (profissionais do PSF e do PACs) o trabalho realizado cotidianamente na rede de Atenção Básica desse município tem sido a estratégia utilizada na intervenção.

A aposta metodológica, então, é, retomando a máxima socioanalítica, transformar para conhecer a experiência atualizada no município de Cariacica em sua potência ontogenética (criação e modificação da realidade), o que desafia o pensamento a superar o modelo de representação. Fazer intervenção, então, é lançar-se em uma experiência de criação de si e de mundos. Nesse sentido, trabalhar no município requer que façamos do "trabalho" de intervenção-apoio uma escuta da experiência do trabalho.

Assim, o método de trabalho é o resultado de uma construção conjunta com aqueles que fazem a demanda de uma transformação. Tal direção metodológica se efetiva na medida em que todos os participantes se engajam nas atividades de análise da situação vivida no município. Cabe a nós, psicólogos, então, estarmos juntos nessa empreitada, oportunizando a criação de situações em que o que vem sendo produzido no campo da saúde em Cariacica, em especial, na Atenção Básica, possa ser pensado, questionado e ganhe outros rumos, quando desejável; e que esses outros rumos, talvez outrora impensados, possam se tornar possíveis e vivíveis.

Buscamos, então, por meio dessa metodologia de trabalho, afirmar um construtivismo radical, visando não às suas regularidades a partir de hipóteses e variáveis controladas, mas às possibilidades de divergir, aos movimentos de inventividade do viver, num constante processo de diferenciação que se atualiza nas situações concretas de trabalho em saúde.

Nesse âmbito, estamos falando de outra forma de lidar com a política como possibilidade de composição de um mundo comum. Um coletivo não está jamais garantido, uma vez que sua existência se faz por meio dos próprios movimentos de sua constituição. É possível apreender o coletivo não mais por oposição a indivíduo, mas a partir de relações estabelecidas entre dois planos que 
constituem a realidade: o plano das formas, plano das realidades constituídas, da organização da realidade, concernente às figuras estabilizadas, com contornos definidos e com caráter constante, e o plano das forças, que é a dimensão potencial de transformação, dimensão instituinte. Tais planos, não mais tomados numa perspectiva de oposição, constroem relações de reciprocidade entre si, viabilizando uma multiplicidade de cruzamentos.

Política, nessa direção, seria a composição de um mundo comum, como processos e, assim, não existem certezas ou saberes inquestionáveis. A direção é outra. Processos políticos criam estratégias que viabilizam as mutações que se insinuam no presente, no concreto das situações vividas pelos humanos, escapando às sobrecodificações. Política não se circunscreve a um domínio particular da sociedade; é movimento de constituição de coletivos. É a partilha, e não a homogeneidade, o que viabiliza o coletivo. No entanto, essa tarefa não se efetiva de forma tranquila, implica controvérsias, embates, conflitos.

Se, como anunciamos no início deste texto, as políticas de governo, os estabelecimentos com seus contornos definidos são efeitos de uma composição do plano das formas com o plano instituinte das forças em luta, as formas não são o ponto de partida para nossas intervenções, pois são resultado desse jogo de forças, conglomerado de vetores. Assim, trabalhar em políticas públicas é acessar esse plano comum, interferir nos processos que constituem as realidades e não partir das realidades como aspectos sempre já dados.

É preciso, então, na contramão das formas totalitárias, apostar em modos de fazer que privilegiem o estar junto, a fiação do comum. Menos que reivindicar sentidos ou modos certos de se fazer ou pensar, fazse necessário partilhar práticas. Isso porque o fato de haver uma política bem delimitada do SUS, e ainda que se possa encontrar a política de humanização descrita em algumas dezenas de cartilhas e documentos, o que se mostra precioso é a possibilidade de tecermos sentidos partilhados que propiciem ao trabalho um brilho singular, singularidade que, por paradoxal que possa parecer, alinhava a produção do comum.

\section{Referências}

Barros, M. de. (2006). Memórias inventadas: a segunda infância. São Paulo: Planeta.

Barros, M. E. B. (2007). Trabalhar: usar de si - sair de si. Interface - 
Comunicação, Saúde, Educação, 11(22), 355-357, maio/ago.

Barros, M. E. B., Guedes, C. R.\& Roza, M. M. (2009). O apoio institucional como método de análise-intervenção no âmbito das políticas públicas de saúde: a experiência em um hospital geral. Revista Ciência e Saúde Coletiva online. Disponível em: <www.cienciaesaudecoletiva.com.br/ artigos/artigo_int.php?id_artigo $=437$ 8ㄱ. Acesso em: 8 jan. 2012.

Benevides, R. \& Passos, E. (2005a). Humanização na saúde: um novo modismo? Interfaces. 9(17), 389-94.

Benevides, R. \& Passos, E. (2005b). A humanização como dimensão pública das políticas de saúde. Ciência e Saúde Coletiva, Rio de Janeiro, 10(3), 561-571, jul./set.

Benevides, R. \& Passos, E. (2009). Por uma política de narratividade. In: E. Passos, V. Kastrup \& L. Escóssia (Org.). Pistas do método da cartografia: pesquisa-intervenção e produção de subjetividade (pp.13149). Porto Alegre: Sulina.

Brasil. Ministério da Saúde. (2006). Portaria $n^{o}$ 648/GM. Aprova a Política Nacional de Atenção Básica, estabelecendo a revisão de diretrizes e normas para a organização da Atenção Básica para o Programa Saúde da Família (PSF) e o Programa Agentes Comunitários de Saúde (PACS). Brasília.

Brasil. Ministério da Saúde. Secretaria de Atenção à Saúde. (2010). Política Nacional de Humanização. Cadernos HumanizaSUS. Brasília, DF: MS. v. 2.

Campos, G. W. de S.(2000). Um método para análise e cogestão de coletivos. São Paulo: Hucitec.

Escóssia, L. \& Tedesco, S. (2009). O coletivo de forças como plano de experiência cartográfica. In: E. Passos, V. Kastrup \& L. Escóssia (Org.). Pistas do método da cartografia: pesquisa-intervenção e produção de subjetividade (pp. 92108). Porto Alegre: Sulina.

Escóssia, L. (2009). O coletivo como plano de criação na saúde pública. Interface - Comunic., Saúde, Educ., 13(1), 689-94.

Foucault, M. (1977). Vigiar e punir. Petrópolis: Vozes.

Gotardo, S. M. (2001). Políticas de comunidade nos terrenos da educação. Dissertação de Mestrado. 
Programa de Pós-Graduação em Psicologia, Universidade Federal do Espírito Santo, Vitória-ES.

Kafka, F. (2002). Comunidade. In: Narrativas do espólio. (pp. 112-113). São Paulo: Companhia das Letras.

Latour, B. (2007). Como falar do corpo? A dimensão normativa dos estudos sobre a ciência. In: J. A. Nunes, \& R. Roque (Org.). Objetos impuros: experiências em estudos sociais da ciência. (pp. 39-61). Porto: Edições Afrontamento.

Passos, E. \& Eirado, A. (2009). Cartografia como dissolução do ponto de vista do observador. In: E. Passos, V. Kastrup \& L. Escóssia (Org.). Pistas do método da cartografia: pesquisaintervenção e produção de subjetividade (pp. 92-108). Porto Alegre: Sulina.

Romano, R. (2005). O público e o privado. In: Heiman, L. S. Ibanhez, L. C. \& Barboza, R. (Org.). O público e o privado na saúde. (pp. 146-162). São Paulo: Hucitec.

Sader, E. S. (2005). O público, o estatal e o privado. In: Heiman, L. S. Ibanhez, L. C. e Barboza, R. (Org.). O público e o privado na saúde. São Paulo: Hucitec.

Santos, M. (2000). Território e sociedade. São Paulo: Editora Fundação Perseu Abramo.

Santos, M. (2008). Metamorfoses do espaço habitado. $6^{a}$ ed. São Paulo: Edusp.

\section{Maria Elizabeth Barros de Barros}

Psicóloga, Pós-Doutora em Saúde Pública pela ENSP. Professora Doutora do Departamento de Psicologia e do Programa de Pós-Graduação em Psicologia Institucional da Universidade Federal do Espírito Santo. Atua nas áreas de Educação e Saúde numa direção institucionalista.

Endereço: Universidade Federal do Espírito Santo/Departamento de Psicologia Av. Fernando Ferrari, no ${ }^{\circ}$ 514, Campus Universitário Alaor Queiroz de Araújo, Goiabeiras, Vitória, Espírito Santo. CEP: 29075-910

E-mail: betebarros@uol.com.br

\section{Ellen Horato do Carmo Pimentel}

Psicóloga, Mestranda do Programa de PósGraduação em Psicologia Institucional da Universidade Federal do Espírito Santo, com atuação na área de subjetividade, políticas públicas, cuidado e saúde pública. 
Pesquisadora que atua no campo da saúde pública e práticas institucionais.

Endereço: Universidade Federal do Espírito Santo/Departamento de Psicologia Av. Fernando Ferrari, no ${ }^{\circ}$ 514, Campus Universitário Alaor Queiroz de Araújo,

Goiabeiras, Vitória, Espírito Santo. CEP: 29075-910

E-mail: ellen_hp@hotmail.com 